\section{Tears of biceps femoris, semimembranosus, and semitendinosus are not equal- a new individual muscle-tendon concept in athletes}

\author{
Lasse Lempainen, Jussi Kosola $(\mathbb{D}$, Ricard Pruna, \\ Juha-Jaakko Sinikumpu, Xavier Valle, Olli Heinonen, \\ Sakari Orava and Nicola Maffulli
}

\begin{abstract}
Objectives: Hamstring injuries are common and can now be accurately diagnosed. In addition, novel surgical indications have been introduced. However, evidence-based guidelines on the hamstring injuries in management of top-level athletes are missing.

Methods: The management methods and outcomes of treatment are classically based on relatively small case series. We discuss a novel concept based on the fact that each tendon of the hamstrings muscle should be managed in an individual fashion. Furthermore, suitable indications for hamstring surgery in athletes are introduced.

Results: The present study introduces modern treatment principles for hamstring injury management. Typical clinical and imagining findings as well as surgical treatment are presented based on a critical review of the available literature and personal experience.

Conclusions: Hamstring injuries should not be considered to be all equal given the complexity of this anatomical region: The three separate tendons are different, and this impacts greatly on the decision-making process and outcomes in athletes.
\end{abstract}

\section{Keywords}

Hamstring injury, surgical treatment, athlete, tendon, biceps femoris, semitendinosus, semimembranosus

Date received: I3 April 2020, accepted: 8 December 2020

\section{Introduction}

The three major muscles forming the hamstring muscle group are biceps femoris (BF), semimembranosus (SM), and semitendinosus (ST). ${ }^{1}$ These individual muscles-BF, SM, ST-serve different functions and exert a specific role and a specific contact times while walking, running, or turning, although their anatomy partially overlaps proximally. ${ }^{2}$

Typically, hamstring injuries are classified according to the location of the injury (i.e. proximal, middle, or distal), and the muscles are often considered as part of the hamstring complex. ${ }^{3,4}$ Injuries of the proximal hamstrings can range from partial to complete tears, and one, two, or all three tendons may avulse from the ischial tuberosity. ${ }^{5-8}$ The higher the grade of injury, the more likely it is for an athlete to undergo operative treatment. 5,6

Hamstring injuries are common in running, sprinting, and jumping events and especially common in soccer': up to five hamstring strains per club per season have been reported. ${ }^{10}$ Most of these injuries can be managed conservatively, and surgery is generally not necessary. ${ }^{3,11,12}$
Scandinavian Journal of Surgery 202I, Vol. I I0(4) 483-49I (C) The Finnish Surgical Society 2021 (c) (i)

Article reuse guidelines: sagepub.com/journals-permissions DOI: I0.1 I77/|457496920984274 journals.sagepub.com/home/sjs

(S)AGE

Corresponding author: Lasse Lempainen

Sports Trauma Research Unit, Hospital Mehiläinen NEO, Joukahaisenkatu 6, Turku, FI 20520, Finland

Department of Physical Activity and Health, Paavo Nurmi Centre, University of Turku, Turku, Finland Email: lasse.lempainen@utu.fi

Jussi Kosola

Department of Physical Activity and Health, Paavo Nurmi Centre, University of Turku, Turku, Finland Department of Surgery,

Kanta-Häme Central Hospital, Hämeenlinna, Finland

\section{Ricard Pruna}

Xavier Valle

FC Barcelona, Medical Services, FIFA Center of Excellence, Barcelona, Spain

Juha-Jaakko Sinikumpu Department of Children and Adolescents, PEDEGO unit and MRC Oulu, Oulu University Hospital and University of Oulu, Oulu, Finland

Olli Heinonen

Department of Physical Activity and Health, Paavo Nurmi Centre, University of Turku, Turku, Finland

Sakari Orava

Sports Trauma Research Unit, Hospital Mehiläinen NEO, Turku, Finland

Department of Physical Activity and Health, Paavo Nurmi Centre, University of Turku, Turku, Finland

\section{Nicola Maffulli}

Department of Musculoskeletal Disorders, University of Salerno School of Medicine, Surgery and Dentistry, Salerno, Italy

Centre for Sports and Exercise Medicine, Queen Mary University of London, London, UK Institute of Science and Technology in Medicine, Keele University School of Medicine, Stoke on Trent, UK 


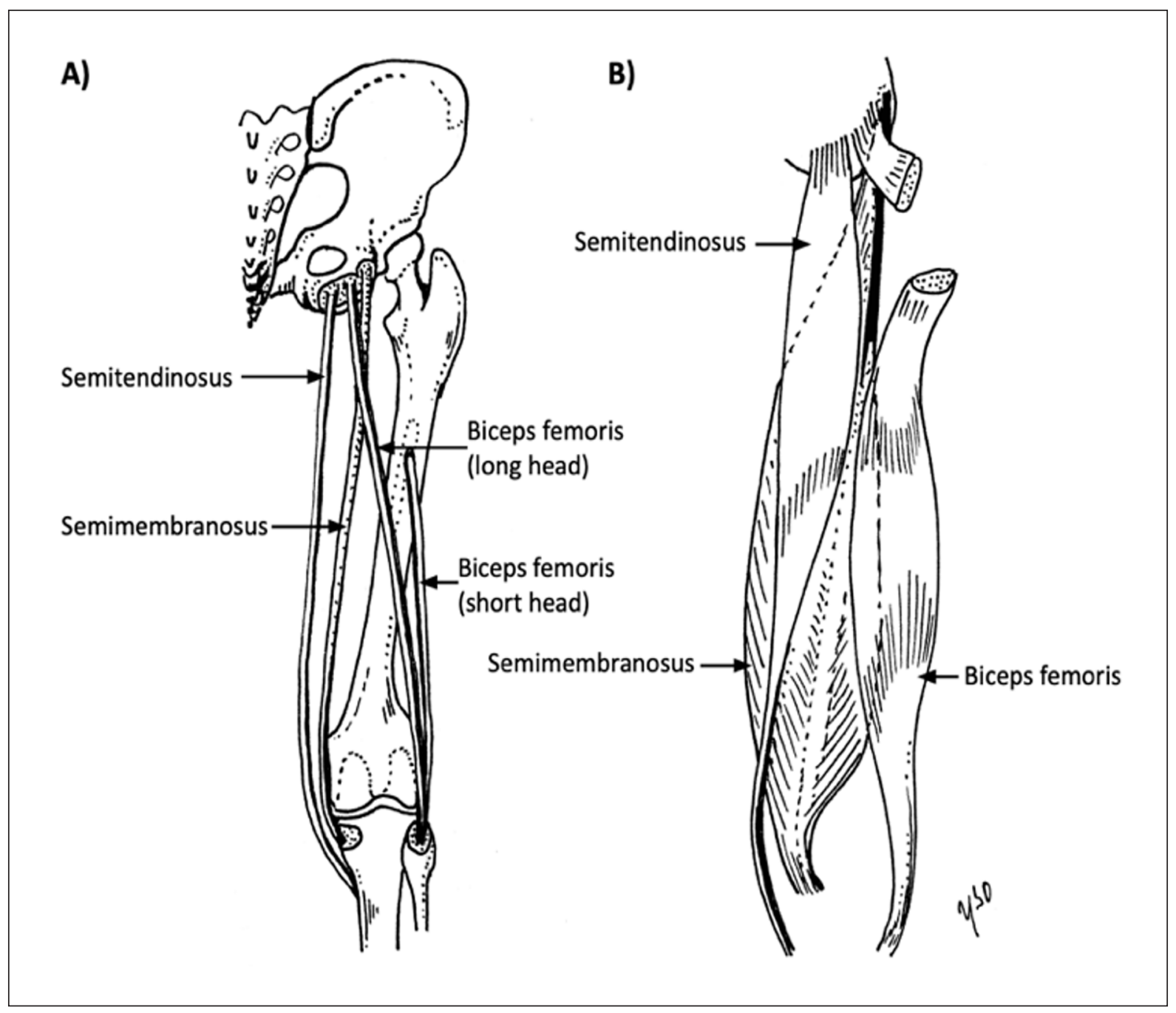

Fig. I. The illustrative drawing of each individual hamstring structure: A) tendons, B) muscles.

However, the optimal treatment of these injuries is still largely unknown, and recurrent hamstring injuries occur far too often. ${ }^{13}$

The aim of this study is to highlight the importance of the individuality of every single hamstring muscle-tendon unit to allow to make a treatment decision in hamstring injuries in athletes. Hamstring tears are not all equal: this concept simplifies making the treatment decision, highlights the importance of each single muscle - tendon unit, and should optimize the treatment results in athletes. We demonstrate the relevance of this concept by showing different individual tendon injuries and giving perspective for their subsequent treatment.

\section{Different functional anatomy of each hamstrings}

The hamstring muscle complex cross the hip and the knee (Fig. 1). With the exception of the short head of BF, the muscles of the posterior aspect of the thigh are mainly hip extensors and knee flexors with subtle rotational features. Distally, these muscles act as horse reins for rotational stabilization and reinforce the capsule while stabilizing the posterior structures such as menisci. ${ }^{14}$

The short head of BF originates at the linea aspera of the posterior aspect of the femur, and the ischial tuberosity is the origin of all the other hamstring muscles. ${ }^{1}$ The SM originates at the anterolateral portion of the ischial tuberosity, and the ST and the long head of the BF originate at the posteromedial parts with a partly conjoined tendon. ${ }^{15}$ Recently, more interest has focused on the central tendon of the hamstring muscles. ${ }^{16,17}$ The central tendons originate at their relevant muscle belly and extend along the entire length of the muscle. ${ }^{1,18}$

The ST has the shortest proximal tendon and the smallest physiological cross-sectional area $\left(8.08 \mathrm{~cm}^{2}\right)$ of the hamstring muscle group. ${ }^{1}$ It attaches distally at the superior aspect of the medial tibiae becoming part of the pes anserinus. 
The SM is the largest muscle of the posterior thigh, with the longest proximal tendon. Its proximal insertion is connected to the ischial tuberosity with a broad aponeurosis. The distal portion consists of tendinous branches joined to the popliteal fascia and the oblique popliteal ligament and attached to the posterior portion of the medial tibial condyle. ${ }^{14}$

The BF exerts more force compared with ST or SM. ${ }^{19}$ Distally, the BF tendon inserts at the anterior and posterior border of the proximal portion of the fibular head. ${ }^{20}$

\section{Injury patterns}

The typical mechanism of hamstring injuries is an eccentric muscle contraction accompanied by forced hyperflexion of the hip and extension of the knee..$^{21,22}$ Patients often report a "popping" sensation when sustaining this injury. ${ }^{23} \mathrm{~A}$ common mechanism for the most severe hamstring injury is a rapid flexion of the hip during an ipsilateral eccentric knee extension, often from a fall while, for example, water skiing resulting in a front split, with a (complete) proximal hamstring rupture. A proximal isolated SM rupture can occur in extreme positions during the extended hip flexion movements performed by ballet dancers. ${ }^{24}$ Isolated SM strain can also occur in slow, apparently well-controlled, stretching exercises performed to the limit of the range of motion when isolated proximal BF injury occurs often, for example, while sprinting.

While these injury patterns are fairly typical in proximal hamstring tears, the distal parts of hamstrings may suffer an injury in a different way. The distal ST has been reported to tear during eccentric hamstring load during high-speed running, when the hamstrings are maximally activated. ${ }^{25}$ At this time, a switch from an eccentric to a concentric muscle contraction mode, with the individual muscles approaching their peak length, makes them most vulnerable to injury.

\section{Treatment decision when hamstring injury occurs-individual muscle concept}

Clear evidence-based guidelines concerning proximal isolated injuries of ST, SM, and BF are not available in the current literature. Studies have introduced injury types which could correlate to poorer prognosis, and therefore treatment algorithms points toward to operative or nonoperative treatments have been made. ${ }^{26,27}$ However, the current literature does not consider these hamstring muscles or tendons individually.

The first step in decision making is to formulate an exact diagnosis (Fig. 2). Clinical findings, mechanism of injury, and patient's history lead to the suspicion of a hamstring injury ${ }^{28,29}$ which is typically verified by magnetic resonance imaging (MRI). MRI allows to detect the location and extent of the injury, the presence of fluid collection, and which muscle and tendon structures are involved. ${ }^{30,31}$ At times, a repeat MRI is needed 2 weeks after injury to obtain more detailed information. ${ }^{17}$ Injuries with a good prognosis after appropriate conservative treatment include injuries at myotendinous junction and low-grade muscle tears. ${ }^{28} \mathrm{~A}$ hamstring injury is a risk factor for chronic and recurrent hamstring injuries ${ }^{28}$; thus, treatment should be well planned, and patients closely followed. ${ }^{32}$ Other possible risk factors include age, untreated muscle strength imbalance, and reduced flexibility. ${ }^{33-38}$

\section{Proximal tendon}

Recently, surgical treatment has become more popular for the management of hamstring injuries. ${ }^{27}$ If a tendon avulses from the ischial tuberosity, the degree of retraction seems to be associated with a poorer outcome ${ }^{39}$ : a retraction greater than $2 \mathrm{~cm}$ is a classical indication for operative treatment in athletes. Retrospective data show that, in 25 patients, conservative and surgical management eventually resulted in a similar acceptable outcome, but initial nonoperative treatment led to conversion to surgery in $40 \%$ of the patients. ${ }^{40}$ Current literature regarding the management of one- or twotendon avulsions is largely lacking, but most of these patients with symptomatic incomplete hamstring avulsions who are unresponsive to conservative management improved after surgical reinsertion. ${ }^{41}$ Early surgical treatment is recommended in complete proximal three-tendon hamstring avulsions (Fig. 3) and two-tendon (BF + ST / BF + SM, Fig. 4) hamstring avulsions ${ }^{6,16,42-44}$, with a highly predictable rate of return to pre-injury level of sports. In proximal non-retracted partial avulsions that remain symptomatic, MRI can show fluid between the ischial tuberosity and the injured tendon attachment, indicating an incomplete healing process. For these patients, surgery is equally also indicated, with a high rate of successful outcomes..$^{5,45}$

In a proximal single-tendon avulsion with retraction from the ischial tuberosity, surgery is also recommended in highlevel athletes regardless of which of the hamstring tendons is involved: BF (Fig. 5A), ST or SM (Fig. 5B). ${ }^{6}$ Without optimal treatment, permanent weakness and pain produce a suboptimal hamstring function.

\section{Distal tendon}

Severe distal tendon injuries are rare compared with proximal hamstring tendon injuries. In athletes, in a complete distal tendon rupture surgery is usually indicated, and nonoperative management carries a high risk of failure. ${ }^{21,46-48} \mathrm{~A}$ complete distal rupture of BF or ST should be repaired anatomically as soon as possible after acute or acute-on-chronic injury $23,25,48,49$ (Figs. 2 and 6). Distal SM avulsion injuries are rare, with a marked negative impact on competitive sports participation. They are typically managed operatively. ${ }^{23,50}$

\section{Central tendon}

Central or free (paramuscular) tendon injuries of the BF tend to become chronic and to recur despite appropriate conservative 


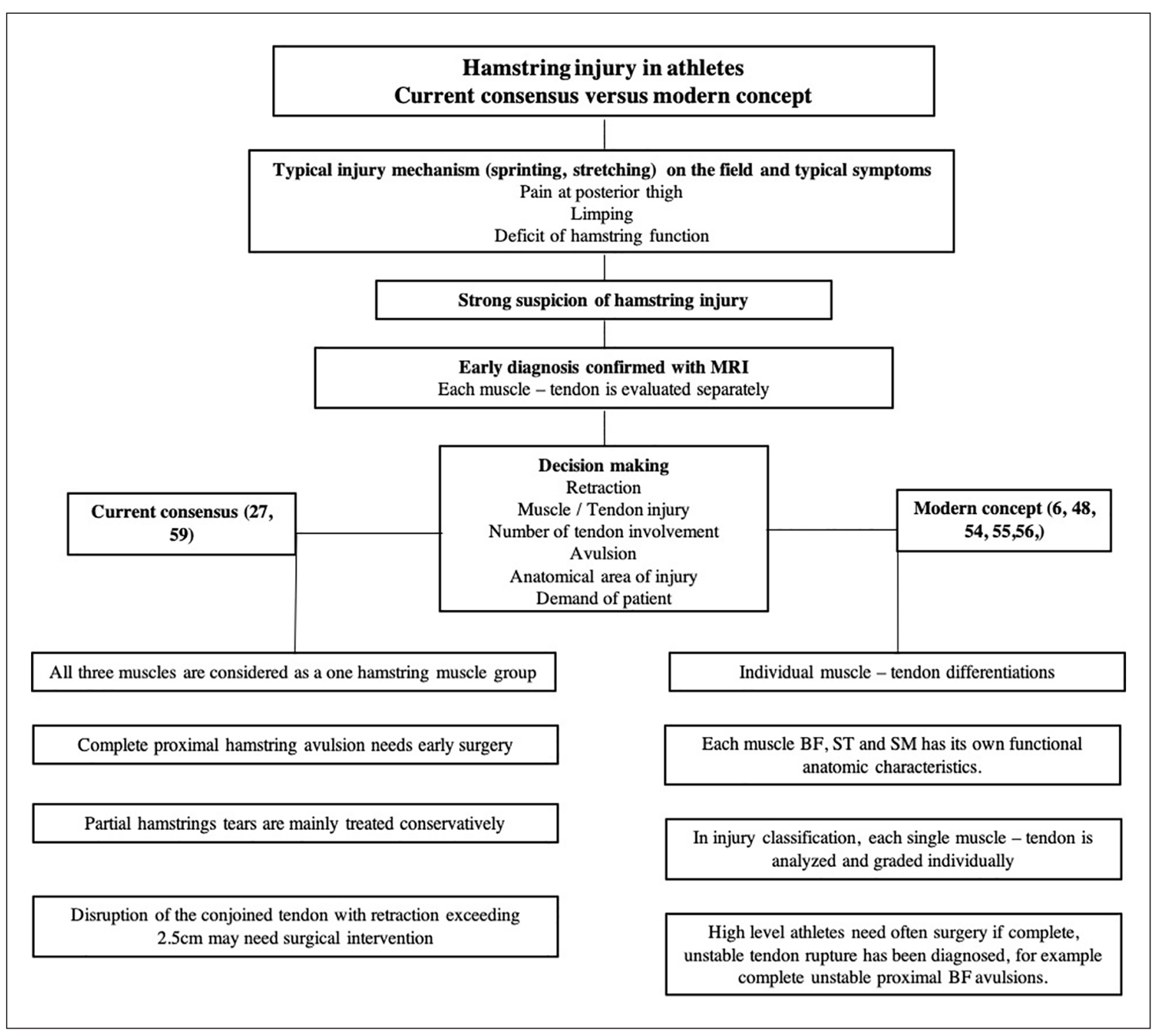

Fig. 2. Comparison between current and modern treatment algorithms based on the present literature.

management ${ }^{17}$ (Fig. 7). In addition, recurrent central tendon injuries produce longer absence from play compared with other hamstring injuries. These central tendon injuries have a high risk of poor healing with nonoperative measures. ${ }^{16}$ If adequate nonoperative management following an acute injury has failed, and recurrent injuries ensue, surgery should be considered.

\section{Nonoperative treatment of proximal hamstring tendon avulsions}

Complete proximal hamstring avulsions have a poor prognosis to heal without adequate treatment, especially in athletes.
Many studies have been conducted to compare whether operative or nonoperative treatments are superior. ${ }^{40,50-52}$ However, it seems that these complete three-tendon avulsion injuries do not heal properly without anatomical repair, especially if there is a clear retraction from the ischial tuberosity. ${ }^{39,53}$ Only some case series have been published on individual proximal hamstring tendon injuries ${ }^{54-56}$ showing superior result of surgery in athletes. Nonoperative treatment of isolated proximal tendon ruptures in athletes has not been fully discussed in the literature. However, most of the hamstring injuries are muscle tissue strains or partial tears with good prognosis when treated by conservative means (modified rest, ice, and progressive rehabilitation). 


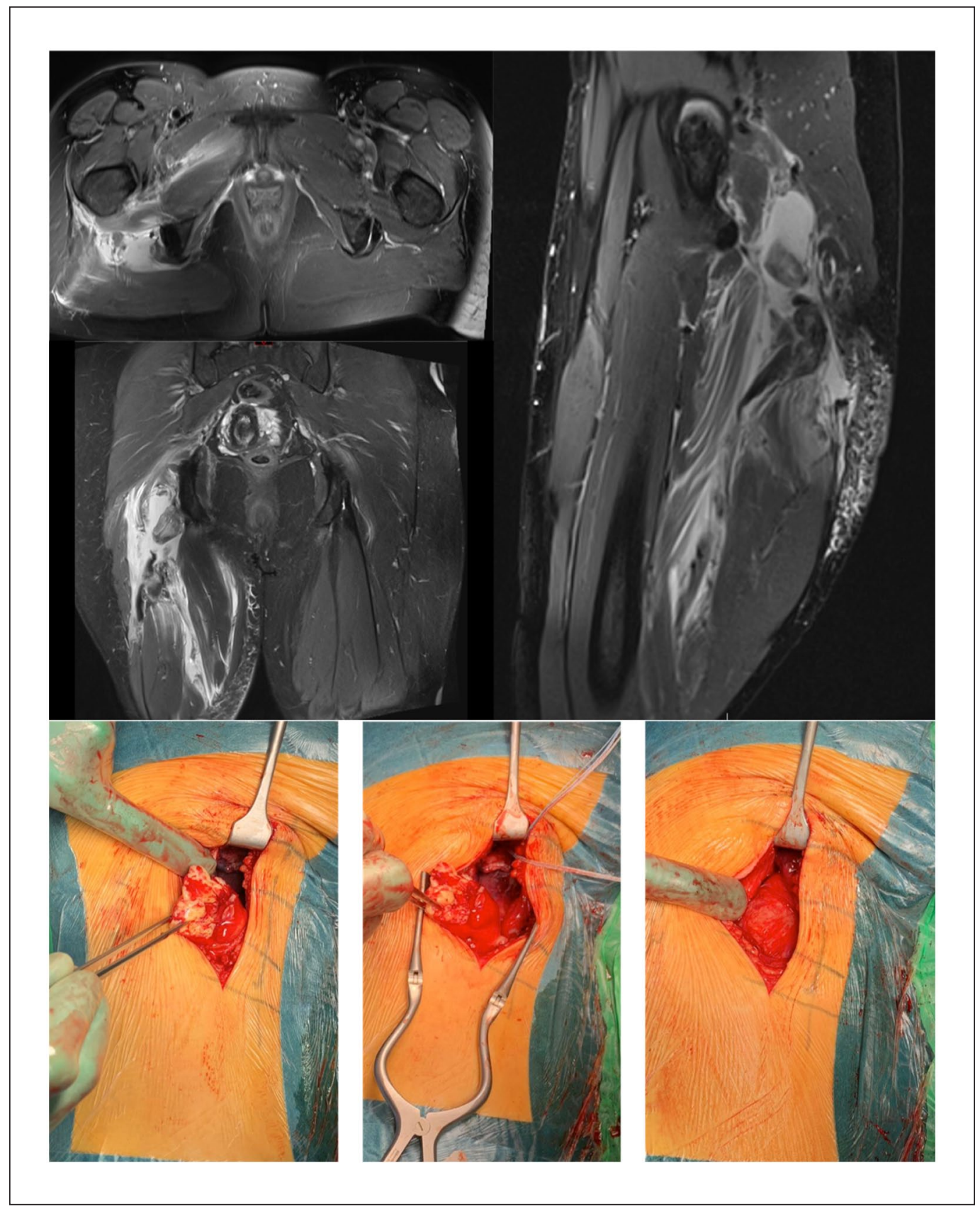

Fig. 3. Complete three-tendon proximal hamstring rupture with a clear retraction at the right side.

\section{Discussion}

The present article introduces the individual muscle-tendon concept in athletes. These injuries are prone to become disabling and chronic if misdiagnosed. ${ }^{32}$ Each hamstring muscle-BF, ST, and SM-has its own function and anatomy, and therefore should be considered individually. When BF, ST, and SM are considered separately and appropriate treatment administered, the risk of recurrent injury might be lower.
Hamstring injuries are typically related to soccer ${ }^{9}$, and recurrent injuries are common, often leading to substantial loss of play..$^{10}$ Hamstring injuries can eventually jeopardize players' careers. Based on our clinical observations, hamstring injuries should be managed according to which individual muscles and tendons are involved. Each hamstring muscle-BF, ST, and SM-has its own function, purpose, and injury pattern. If one of these three tendons is completely ruptured, it may permanently impair athlete's performance and often also cause significant pain. These injuries should be 


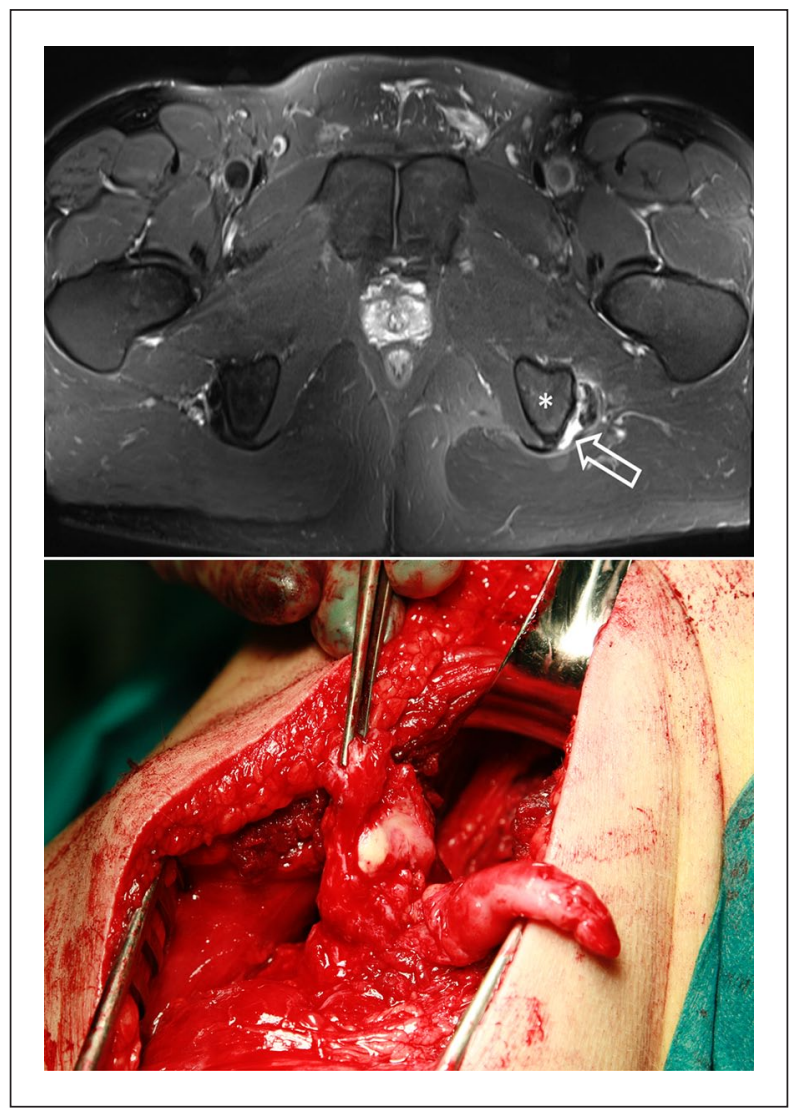

Fig. 4. Perioperative image of the complete proximal twotendon (BF and ST)—rupture. Arrow showing the ruptured area.

probably managed surgically in top-level athletes. In practice, we should deal and manage each muscle and tendon of the hamstring complex individually, similar to what already happens in the gastrocnemius / soleus / Achilles muscle-tendon complex, and consider BF, ST, and SM and each of their tendons separately.

Different classifications of hamstring injuries are available.,, 57 However, clinical and MRI data can contrast with each other. ${ }^{58}$ The MLG-R classification takes into consideration the mechanism of injury (M), location of injury (L), level of severity $(G)$, and number of muscle re-injuries (R) and is based on an MRI. Although the return to play seems to somewhat correlate to the higher grade of injury, the choice of treatment should be considered individually.

Typically, avulsion of the three attachment tendons from the ischial tuberosity is considered an indication for surgery, ${ }^{59}$ but the treatment strategy with partial or single proximal tendon avulsion can be debated. ${ }^{40,50}$ In athletes, the loss of time to return to play and the rate of recurrence should be minimized. High-quality studies regarding individual hamstring tendon avulsion are scarce. Recently, Ayuob et al have published case series of operative treatment to avulsions of single tendon..$^{55}$

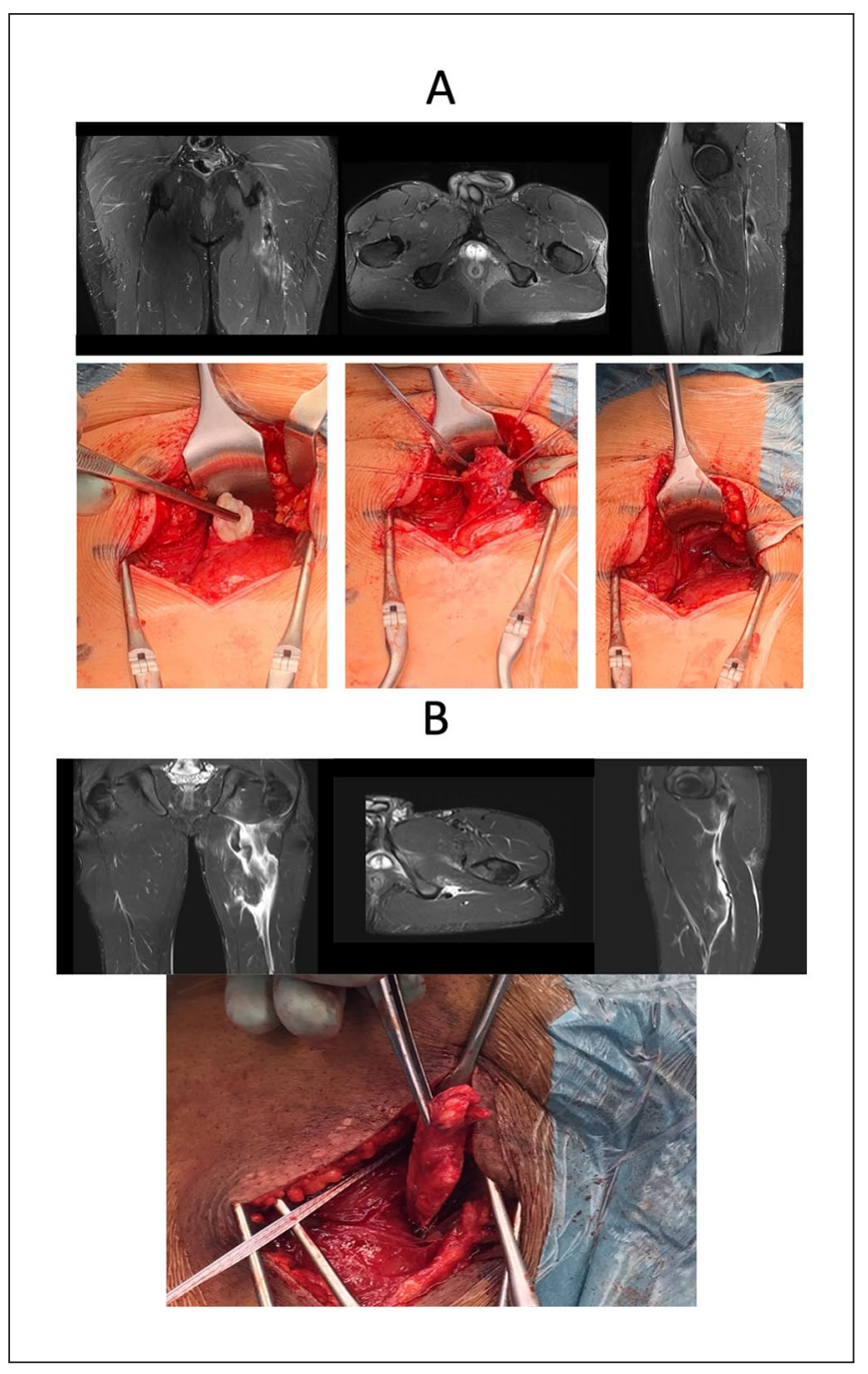

Fig. 5. Isolated complete proximal single-tendon rupture: A) BF (MRI and perioperative images), B) SM (MRI and perioperative images).

These results are in line with other earlier studies. ${ }^{6,54}$ However, level 1 evidence is lacking as comparative studies do not exists in the current literature.

In conclusion, based on the present knowledge of anatomy and the different functions of each of the muscles of the posterior aspect of the thigh, and the capability of MRI to allow to formulate an accurate diagnosis, the term "hamstring injury" seems somewhat inaccurate. To improve the standard level of the treatment, especially in athletes, we should precisely identify which individual muscle(s) is(are) affected. Formulating a precise diagnosis would prompt to talk about $\mathrm{BF}, \mathrm{SM}$, or ST injury, or a combination of them. Complete single-tendon avulsions-BF, ST, SM, or their combined injury - in high-performance athletes could lead to a marked loss of function and chronic disability, and therefore operative treatment should often be considered. 


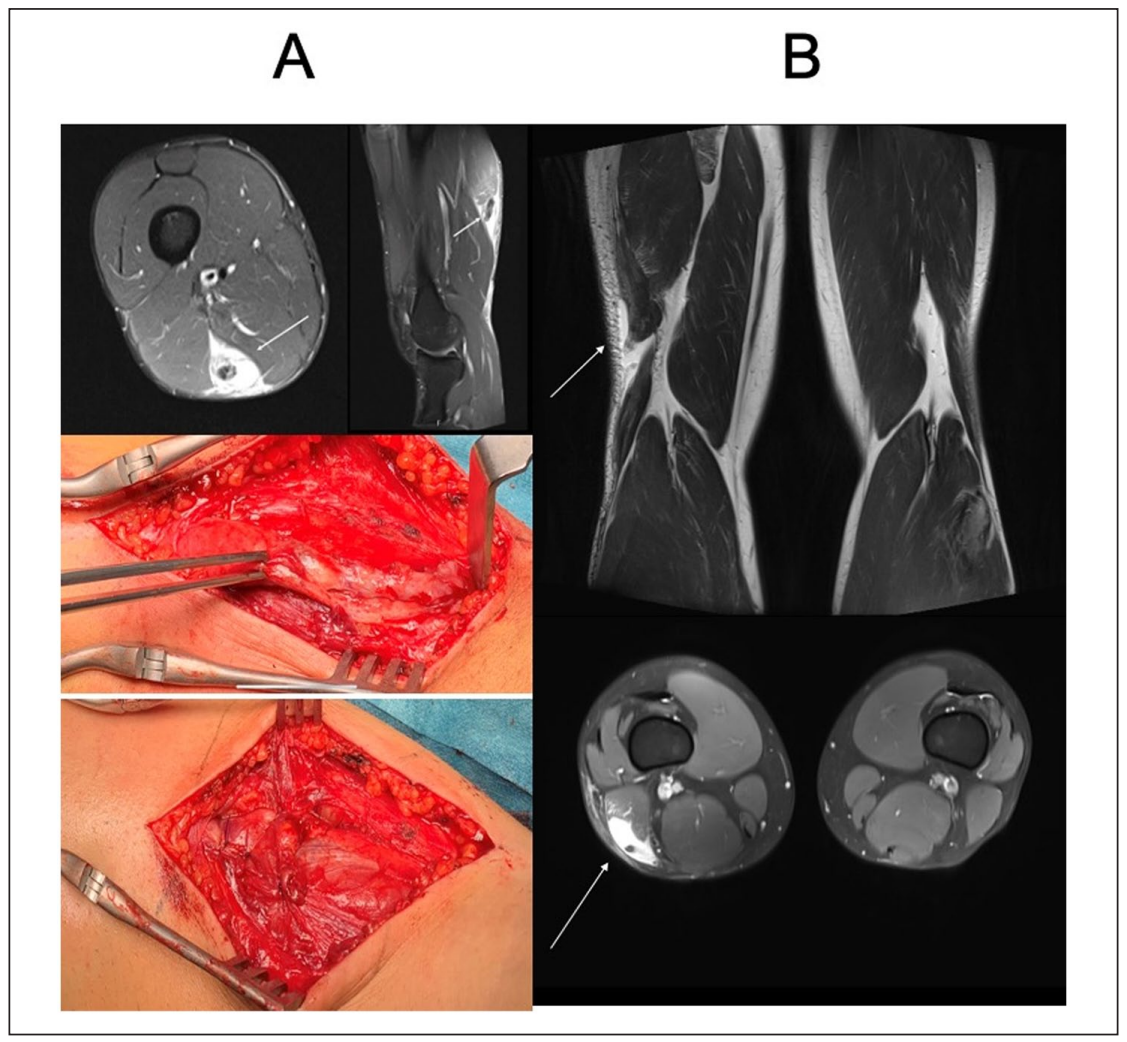

Fig. 6. A) Distal tendon rupture of the $S T$ (MRI and perioperative images before and after repair) and $B$ ) distal $M T J$ area rupture of the BF (MRI images, arrows indicate the retracted muscle belly and tendon stump).

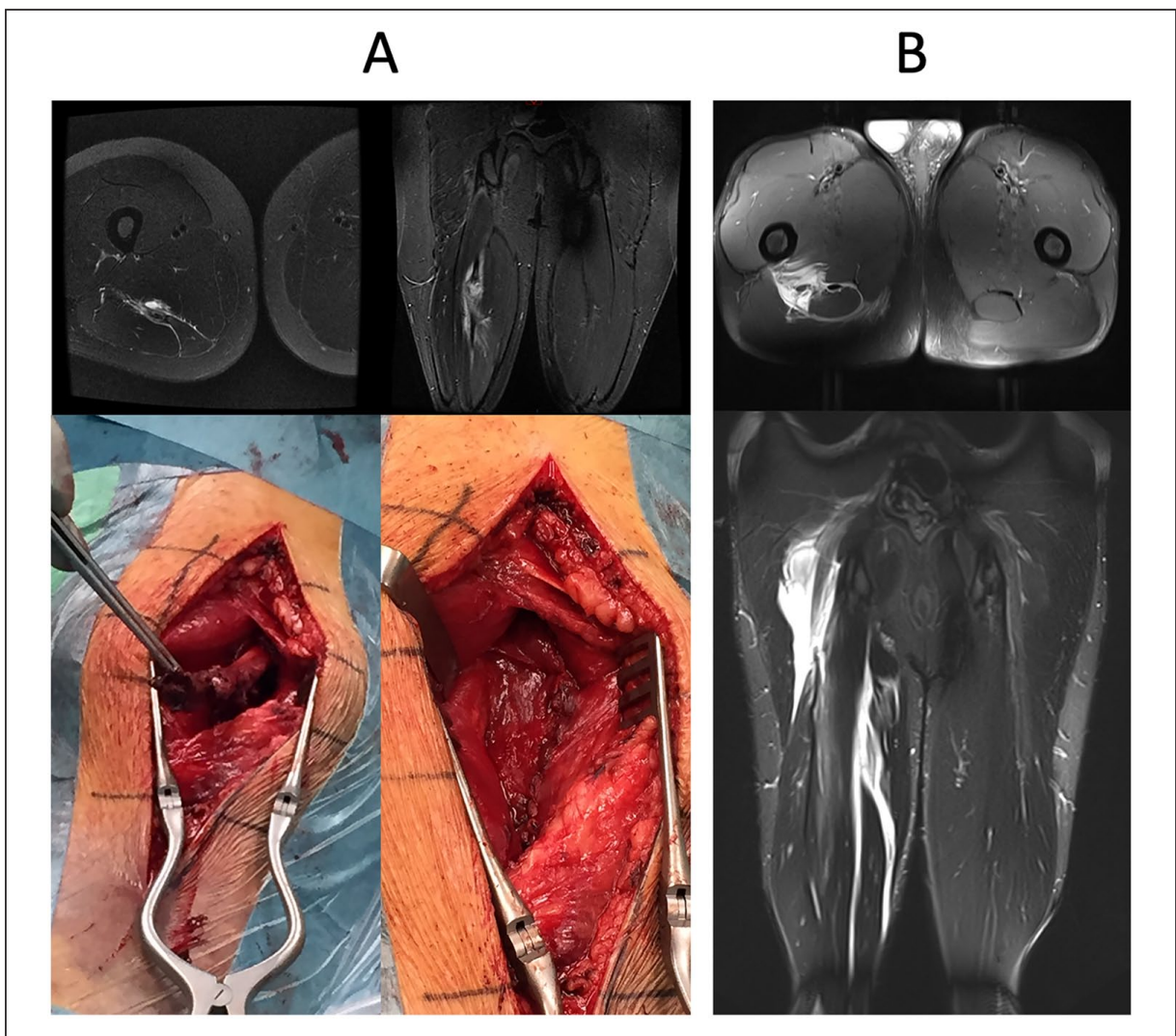

Fig. 7. A) Central tendon rupture of the SM (recurrent injury, MRI and perioperative images before and after repair) and B) BF (acute injury, MRI). 


\section{Declaration of conflicting interests}

The author(s) declared no potential conflicts of interest with respect to the research, authorship, and/or publication of this article.

\section{Funding}

The author(s) received no financial support for the research, authorship, and/or publication of this article.

\section{ORCID iD}

Jussi Kosola (iD https://orcid.org/0000-0003-4428-7472

\section{References}

1. Woodley SJ, Mercer SR: Hamstring muscles: Architecture and innervation. Cells Tissues Organs 2005; 179(3): 125-141.

2. Thelen DG, Chumanov ES, Hoerth DM et al: Hamstring muscle kinematics during treadmill sprinting. Med Sci Sports Exerc 2005; 37(1): 108-114.

3. Maffulli N, Oliva F, Frizziero A et al: ISMuLT guidelines for muscle injuries. Muscles Ligaments Tendons J 2014; 3(4): 241-249.

4. Chan O, Del Buono A, Best TM et al: Acute muscle strain injuries: A proposed new classification system. Knee Surg Sports Traumatol Arthrosc 2012; 20(11): 2356-2362.

5. Lempainen L, Johansson K, Banke IJ et al: Expert opinion: Diagnosis and treatment of proximal hamstring tendinopathy. Muscles Ligaments Tendons J 2015; 5(1): 23-28.

6. Lempainen L, Banke IJ, Johansson K et al: Clinical principles in the management of hamstring injuries. Knee Surg Sports Traumatol Arthrosc 2015; 23(8): 2449-2456.

7. Pollock N, James SL, Lee JC et al: British athletics muscle injury classification: A new grading system. Br J Sports Med 2014; 48(18): 1347-1351.

8. Valle $\mathrm{X}$, Tol H, Hamilton B: Muscle injury classification. From muscle injuries clinical guide 3.0, https://muscletechnetwork.org/ wp-content/uploads/2015/04/MUSCLE-INJURIES-CLINICALGUIDE-3.0-LAST-VERSION.pdf (accessed January 2015).

9. Ekstrand J, Hagglund M, Walden M: Epidemiology of muscle injuries in professional football (soccer). Am J Sports Med 2011; 39(6): 1226-1232.

10. Woods C, Hawkins RD, Maltby S et al: The football association medical research programme: An audit of injuries in professional football-Analysis of hamstring injuries. Br J Sports Med 2004; 38(1): 36-41.

11. Järvinen TAH, Järvinen M, Kalimo H: Regeneration of injured skeletal muscle after the injury. Muscles Ligaments Tendons J 2013; 3(4): 337-345.

12. Ahmad CS, Redler LH, Ciccotti MG et al: Evaluation and management of hamstring injuries. Am J Sports Med 2013; 41(12): 2933-2947.

13. Ekstrand J, Hagglund M, Walden M: Injury incidence and injury patterns in professional football: The UEFA injury study. Br J Sports Med 2011; 45(7): 553-558.

14. Beltran J, Matityahu A, Hwang K et al: The distal semimembranosus complex: Normal MR anatomy, variants, biomechanics and pathology. Skeletal Radiol 2003; 32(8): 435-445.

15. Sato K, Nimura A, Yamaguchi K et al: Anatomical study of the proximal origin of hamstring muscles. J Orthop Sci 2012; 17(5): 614-618.
16. Brukner P, Connell D: "Serious thigh muscle strains": Beware the intramuscular tendon which plays an important role in difficult hamstring and quadriceps muscle strains. Br J Sports Med 2016; 50(4): 205-208.

17. Lempainen L, Kosola J, Pruna R et al: Central tendon injuries of hamstring muscles: Case series of operative treatment. Orthop J Sports Med 2018; 6(2): 2325967118755992.

18. Garrett WE Jr, Califf JC, Bassett FH 3rd: Histochemical correlates of hamstring injuries. Am J Sports Med 1984; 12(2): 98-103.

19. Dolman B, Verrall G, Reid I: Physical principles demonstrate that the biceps femoris muscle relative to the other hamstring muscles exerts the most force: Implications for hamstring muscle strain injuries. Muscles Ligaments Tendons J 2014; 4(3): 371-377.

20. Branch EA, Anz AW: Distal insertions of the biceps femoris-A quantitative analysis. Orthop J Sports Med 2015; 3(9): 2325967115602255.

21. Blakeney WG, Zilko SR, Edmonston SJ et al: A prospective evaluation of proximal hamstring tendon avulsions: Improved functional outcomes following surgical repair. Knee Surg Sports Traumatol Arthrosc 2017; 25(6): 1943-1950.

22. Stevens MA, El-Khoury GY, Kathol MH et al: Imaging features of avulsion injuries. Radiographics 1999; 19(3): 655-672.

23. Sivasundaram L, Matcuk GR Jr, White EA et al: Partial semitendinosus tendon tear in a young athlete: A case report and review of the distal semitendinosus anatomy. Skeletal Radiol 2015; 44(7): 1051-1056.

24. Askling C, Tengvar M, Saartok T et al: Sports related hamstring strains-two cases with different etiologies and injury sites. Scand J Med Sci Sports 2000; 10(5): 304-307.

25. Lempainen L, Sarimo J, Mattila K et al: Distal tears of the hamstring muscles: Review of the literature and our results of surgical treatment. Br J Sports Med 2007; 41(2): 80-83; discussion83.

26. Fournier-Farley $\mathrm{C}$, Lamontagne $\mathrm{M}$, Gendron $\mathrm{P}$ et al: Determinants of return to play after the nonoperative management of hamstring injuries in athletes: A systematic review. Am J Sports Med 2016; 44(8): 2166-2172.

27. Arner JW, McClincy MP, Bradley JP: Hamstring injuries in athletes: Evidence-based treatment. J Am Acad Orthop Surg 2019; 27(23): 868-877.

28. Malliaropoulos N, Papacostas E, Kiritsi O et al: Posterior thigh muscle injuries in elite track and field athletes. Am J Sports Med 2010; 38(9): 1813-1819.

29. Valle X, Malliaropoulos N, Parraga Botero JD et al: Hamstring and other thigh injuries in children and young athletes. Scand J Med Sci Sports 2018; 28(12): 2630-2637.

30. Entwisle T, Ling Y, Splatt A et al: Distal musculotendinous T junction injuries of the biceps femoris: An MRI case review. Orthop J Sports Med 2017; 5(7): 2325967117714998.

31. Greenky M, Cohen SB: Magnetic resonance imaging for assessing hamstring injuries: Clinical benefits and pitfallsA review of the current literature. Open Access J Sports Med 2017; 8: 167-170.

32. Brukner $\mathrm{P}$, Nealon A, Morgan $\mathrm{C}$ et al: Recurrent hamstring muscle injury: Applying the limited evidence in the professional football setting with a seven-point programme. Br J Sports Med 2014; 48(11): 929-938. 
33. Henderson G, Barnes CA, Portas MD: Factors associated with increased propensity for hamstring injury in English Premier League soccer players. J Sci Med Sport 2010; 13(4): 397-402.

34. van Beijsterveldt AM, van de Port IG, Vereijken AJ et al: Risk factors for hamstring injuries in male soccer players: A systematic review of prospective studies. Scand J Med Sci Sports 2013; 23(3): 253-262.

35. Engebretsen AH, Myklebust G, Holme I et al: Intrinsic risk factors for hamstring injuries among male soccer players: A prospective cohort study. Am J Sports Med 2010; 38(6): 1147-1153.

36. Hagglund M, Walden M, Ekstrand J: Previous injury as a risk factor for injury in elite football: A prospective study over two consecutive seasons. Br J Sports Med 2006; 40(9): 767-772.

37. Fousekis K, Tsepis E, Poulmedis P et al: Intrinsicrisk factors of non-contact quadricepsand hamstring strains in soccer: A prospective study of 100 professional players. Br J Sports Med 2011; 45(9): 709-714.

38. Tokutake G, Kuramochi R, Murata $\mathrm{Y}$ et al: The risk factors of hamstring strain injury induced by high-speed running. J Sports Sci Med 2018; 17(4): 650-655.

39. Wood DG, Packham I, Trikha SP et al: Avulsion of the proximal hamstring origin. J Bone Joint Surg Am 2008; 90: 2365 2374.

40. Piposar JR, Vinod AV, Olsen JR et al: High-grade partial and retracted $(<2 \mathrm{~cm})$ proximal hamstring ruptures nonsurgical treatment revisited. Orthop J Sports Med 2017; 5(2): 2325967117692507.

41. Aldridge SE, Heilpern GN, Carmichael JR et al: Incomplete avulsion of the proximal insertion of the hamstring: Outcome two years following surgical repair. J Bone Joint Surg Br 2012; 94(5): 660-662.

42. Orava S, Kujala UM: Rupture of the ischial origin of the hamstring muscles. Am J Sports Med 1995; 23(6): 702-705.

43. Sandmann GH, Hahn D, Amereller M et al: Mid-term functional outcome and return to sports after proximal hamstring tendon repair. Int J Sports Med 2016; 37(7): 570-576.

44. Sarimo J, Lempainen L, Mattila K et al: Complete proximal hamstring avulsions: A series of 41 patients with operative treatment. Am J Sports Med 2008; 36(6): 1110-1115.

45. McGregor C, Ghosh S, Young DA et al: Traumatic and overuse injuries of the ischial origin of the hamstrings. Disabil Rehabil 2008; 30(20-22): 1597-1601.
46. Cooper DE, Conway JE: Distal semitendinosus ruptures in elite-level athletes: Low success rates of nonoperative treatment. Am J Sports Med 2010; 38(6): 1174-1178.

47. Hallen A, Ekstrand J: Return to play following muscle injuries in professional footballers. J Sports Sci 2014; 32(13): $1229-1236$

48. Kayani B, Ayuob A, Begum F et al: Surgical repair of distal musculotendinous $\mathrm{T}$ junction injuries of the biceps femoris. Am J Sports Med 2020; 48(10): 2456-2464.

49. Knapik DM, Metcalf KB, Voos JE: Isolated tearing and avulsion of the distal biceps femoris tendon during sporting activities: A systematic review. Orthop J Sports Med 2018; 6(7): 2325967118781828.

50. Bodendorfer BM, Curley AJ, Kotler JA et al: Outcomes after operative and nonoperative treatment of proximal hamstring avulsions: A systematic review and meta-analysis. Am J Sports Med 2018; 46(11): 2798-2808.

51. Shambaugh BC, Olsen JR, Lacerte E et al: A comparison of nonoperative and operative treatment of complete proximal hamstring ruptures. Orthop J Sports Med 2017; 5(11): 2325967117738551.

52. Harris JD, Griesser MJ, Best TM et al: Treatment of proximal hamstring ruptures-A systematic review. Int J Sports Med 2011; 32(7): 490-495.

53. Cohen S, Bradley J: Acute proximal hamstring rupture. J Am Acad Orthop Surg 2007; 15(6): 350-355.

54. Lempainen L, Sarimo J, Heikkila J et al: Surgical treatment of partial tears of the proximal origin of the hamstring muscles. $\mathrm{Br}$ J Sports Med 2006; 40(8): 688-691.

55. Ayuob A, Kayani B, Haddad FS: Acute surgical repair of complete, nonavulsion proximal semimembranosus injuries in professional athletes. Am J Sports Med 2020; 48(9): 2170-2177.

56. Ayuob A, Kayani B, Haddad FS: Musculotendinous junction injuries of the proximal biceps femoris: A prospective study of 64 patients treated surgically. Am J Sports Med 2020; 48(8): 1974-1982.

57. Hamilton B, Valle X, Rodas $\mathrm{G}$ et al: Classification and grading of muscle injuries: A narrative review. Br J Sports Med 2015; 49(5): 306.

58. Ekstrand J, Healy JC, Walden $\mathrm{M}$ et al: Hamstring muscle injuries in professional football: The correlation of MRI findings with return to play. Br J Sports Med 2012; 46(2): 112-117.

59. Heer ST, Callander JW, Kraeutler MJ et al: Hamstring injuries: Risk factors, treatment, and rehabilitation. J Bone Joint Surg Am 2019; 1101(9): 843-853. 